\title{
Different mechanisms underlying divergent responses of autotrophic and heterotrophic respiration to long-term throughfall reduction in a warm-temperate oak forest
}

Jinglei Zhang ( $\sim$ zhangjinglei910524@163.com )

Chinese Academy of Forestry Institute of Forest Ecology Environment and Protection https://orcid.org/0000-0002-4725-7909

Shirong Liu

Chinese Academy of Forestry Institute of Forest Ecology Environment and Protection Cuiju Liu

Chinese Academy of Forestry Institute of Forest Ecology Environment and Protection Hui Wang

Chinese Academy of Forestry Institute of Forest Ecology Environment and Protection Junwei Luan

International Center for Bamboo and Rattan

Xiaojing Liu

Baotianman Natural Reserve Administration

Xinwei Guo

Chinese Academy of Forestry Institute of Forest Ecology Environment and Protection

\section{Baoliang Niu}

Chinese Academy of Forestry Institute of Forest Ecology Environment and Protection

\section{Research Article}

Keywords: Prolonged drought, CO2 efflux, Fine root, Bacterial community, Fungal community

Posted Date: March 24th, 2021

DOI: https://doi.org/10.21203/rs.3.rs-333150/v1

License: (c) (1) This work is licensed under a Creative Commons Attribution 4.0 International License. Read Full License 
Version of Record: A version of this preprint was published at Forest Ecosystems on July 6th, 2021. See the published version at https://doi.org/10.1186/s40663-021-00321-z. 


\section{Abstract}

Background: There are many studies on disentangling the responses of autotrophic (AR) and heterotrophic (HR) respiration components of soil respiration (SR) to long-term drought, but few studies have focused on the mechanisms underlying its responses.

Methods: To explore the impact of prolonged drought on AR and HR, We conducted the 2-year measurements on soil $\mathrm{CO}_{2}$ effluxes in the 7th and 8th year of manipulated throughfall reduction (TFR) in a warm-temperate oak forest.

Results: Our results showed long-term TFR decreased HR, which was positively related to bacterial richness. More importantly, some bacterial taxa such as Novosphingobium and norank Acidimicrobiia, and fungal Leptobacillium were identified as major drivers of HR. In contrast, long-term TFR increased AR due to the increased fine root biomass and production. The increased AR accompanied by decreased HR appeared to counteract each other, and subsequently resulted in the unchanged SR under the TFR.

Conclusions: Our study shows that HR and AR respond in the opposite directions to long-term TFR. Soil microorganisms and fine roots account for the respective mechanisms underlying the divergent responses of $H R$ and AR to long-term TFR. This highlights the contrasting responses of AR and HR to prolonged drought should be taken into account when predicting soil $\mathrm{CO}_{2}$ effluxes under future droughts.

\section{Background}

Climate models predict widespread alterations in precipitation regimes, including longer, more intense droughts in the next decades (IPCC, 2013). The increased drought has a considerable effect on terrestrial carbon (C) cycling (Tian et al., 2000; Batson et al., 2015; Vidon et al., 2016), particular to soil respiration $(\mathrm{SR})$, which is the largest $\mathrm{CO}_{2}$ flux from terrestrial ecosystems back to the atmosphere (Janssens et al., 2001). Although multitudes of drought experiments have been conducted to explore the effect of drought on SR, the results of previous studies have been variable, including increase (Cleveland et al., 2010; Zhang et al., 2015), decrease (Schindlbacher et al., 2012; Selsted et al., 2012), and no change (Davidson et al., 2008; Lu et al., 2017). These inconsistent and often contradictory results constrain our understanding of feedbacks between soil $\mathrm{C}$ cycling and climate change.

Predicting the response of SR to drought is inherently difficult as SR is a combination of respiration associated with root activity (autotrophic respiration, AR) and soil organic matter (SOM) decomposition (heterotrophic respiration, HR) (Wang et al., 2014). Due to the difference in turnover times and control factors of plant and soil C pools, AR and HR often responded differently to drought (Borken et al., 2006; Huang et al., 2018; Sun et al., 2019). It has been shown that drought reduced AR, and thus SR, but had no effect on HR in a dry temperate forest (Hinko-Najera et al., 2015). Another study in a subtropical forest found drought decreased both AR and HR, and hence SR (Zhou et al., 2020). A previous study in a warmtemperate oak forest also suggested that drought increased AR but not HR, and therefore SR at a small scale (e.g., $4 \mathrm{~m} \times 4 \mathrm{~m}$ roof) throughfall reduction (Liu et al., 2016). All of these indicate roots and soil 
microbes have differential sensitivities to drought, and ultimately determine the direction of SR in response to drought in different ecosystems (Luo and Zhou, 2006). Nevertheless, the mechanisms underlying different responses of $A R$ and $H R$ to drought are far from clear, which limits our comprehension of whether soil acts as a $\mathrm{C}$ sink or $\mathrm{C}$ source in the scenario of increased droughts.

Although these past studies provide important insights into the effects of drought on SR and its components, they have almost conducted for short-term drought periods, rather than long-term consecutive drought. The long-term experiments are crucial to revealing not only the transient responses of $A R$ and $H R$ to drought but also the adaptive response. A throughfall reduction experiment in a tropical rainforest found that drought increased SR during the first 3 years (Zhang et al., 2015), but did not change SR after 6 years of continuous drought because of the increased HR and decreased AR (Zhou et al., 2019). Thus, the drought responses of AR and HR may shift with the duration of drought, with consequences for SR (Metcalfe et al., 2007; da Costa et al., 2013).

Lu et al. (2017) reported that TFR did not affect HR during the first 4 years, and only increased AR as well as $\mathrm{SR}$ in the second year in this warm-temperate oak forest. In the present study, we explored if TFR still had a slight effect on SR after 6-year consecutive TFR treatment, and if AR and HR responded differently to long-term TFR. Soil microbial community attributes (e.g., diversity, abundance) as well as fine root properties (e.g., biomass, production) were studied to reveal the mechanisms underlying the responses of AR and HR to long-term TFR.

\section{Materials And Methods}

\section{Study site}

The research was conducted at the Baotianman Forest Ecosystem Research Station (111 ${ }^{\circ} 92^{\prime} \mathrm{E}, 33^{\circ} 49^{\prime}$ $\mathrm{N})$, Henan province, central China. The study area has a continental monsoon climate and has four distinctive seasons, with humid and hot summer, and dry and cold winter. The annual average air temperature is $15.1^{\circ} \mathrm{C}$, and the annual precipitation is $894 \mathrm{~mm}$ (1400 $\mathrm{m}$ a.s.I.) (Liu et al., 2016). The upland soil is dominated by Haplic luvisol and soil pH ranged from 4.4-5.1 (Luan et al., 2011; Lu et al., 2017). The soil has a sandy loam texture with $57-62 \%$ sand, $11-13 \%$ slit, and $27-30 \%$ clay (Luan et al., 2011). The dominant deciduous broadleaf tree species include Quercus variabilis, Quercus aliena var. acuteserrata, and Fagus engleriana, and coniferous tree species include Pinus armandii, Pinus tabulaeformis, and Pinus massoniana.

\section{Experimental design}

In the spring of 2013 , six plots $(20 \mathrm{~m} \times 20 \mathrm{~m}$ ) were set up in a 60-year-old oak (Q. aliena var. acuteserrata) forest. Three plots with the ambient environment were designed as controls ("control") and three plots were assigned to manipulated throughfall reduction ("TFR"). Detailed information for the TFR experiment refers to Lu et al., 2017. Briefly, about 160 shelter-panels $(0.5 \mathrm{~m} \times 3 \mathrm{~m})$, covering $50 \%$ of the plot area, were installed in each TFR plot during the growing seasons (May-October) from 2013 to 2017. In the 
spring of 2018 , we adjusted the magnitude of TFR from $50 \%$ to $70 \%$. We inserted plastic barriers to a depth of $0.7 \mathrm{~m}$ around each TFR plot to inhibit the subsurface flow of water, and extended plastic flashing $5 \mathrm{~cm}$ above the ground to prevent overland flow. A buffer zone of $2.5 \mathrm{~m}$ width is set off along the inner edge of each plot and no measurements were made in the buffer zone. Litter that fell on the panels was collected weekly and distributed evenly throughout the plot to avoid variations in litter input on the ground.

\section{Measurements of SR and its components}

The HR was estimated using the trenching method as described by Lu et al. (2017). Briefly, five subplots $(3 \mathrm{~m} \times 3 \mathrm{~m}$ ) were randomly assigned in each plot in March 2013 to measure HR. Trenches were dug about $1 \mathrm{~m}$ deep and placed plastic plates (5 mm thick) to inhibit root in-growth. In October of 2018, we dug the trenches again at the original position. To measure SR and HR, two PVC collars $(19.6 \mathrm{~cm}$ inner diameter, $8 \mathrm{~cm}$ height) were installed $5 \mathrm{~cm}$ into the soil in each un-trenched and trenched subplot. We estimated AR as the difference between SR and HR.

The SR and HR were measured once a month during the growing seasons from 2019 to 2020 using a Li8100 soil $\mathrm{CO}_{2}$ flux system (LI-COR Inc., Lincoln, NE, USA). In the meanwhile, soil temperature (ST) and soil moisture (SM) were manually measured by a portable temperature probe and soil moisture gauge (MPKitBN, TZT Inc., Nantong, China) at three locations around each collar at $0-5 \mathrm{~cm}$ depth. Besides, in each plot, an EM50 data logger was installed with five 5TM soil temperature and moisture combined probes to continuously measure ST and SM at 30 min intervals. The precipitation data were obtained from the automatic weather station at Baotianman Forest Ecosystem Research Station, about $1 \mathrm{~km}$ away from the experimental plots.

\section{Soil and fine root characteristics}

Soil samples were collected in August 2019 and August 2020 within the same day of SR measurements to examine the effects of TFR on soil microbial communities and fine root characteristics. Two soil samples $(0-10 \mathrm{~cm})$ from each subplot were collected using soil augers (inner diameter $3.8 \mathrm{~cm})$. The fresh soil samples sieved by $2 \mathrm{~mm}$ mesh were used for chemical and microbial analyses. Fine root biomass ( $<2 \mathrm{~mm}$ ) was oven-dried to a constant weight and then weighted. The soil organic carbon (SOC) and total nitrogen $(\mathrm{N})$, fine root $\mathrm{C}$ and $\mathrm{N}$ content were determined using an elemental analyzer. The soil total phosphorus $(P)$ and fine root $P$ contents were measured using the alkaline fusion molybdenumantimony colorimetry (Bao, 2000). Fine root nonstructural carbohydrates (NSC): soluble sugar and starch were determined using the anthrone colorimetric method (Gao, 2006). Soil microbial biomass $C$ (MBC) and nitrogen (MBN) were analyzed by chloroform fumigation extraction method with conversion factors of 0.45 (Wu et al., 1990) and 0.54 (Vance et al., 1987), respectively. Soil $\beta$-glucosidase, polyphenolase, peroxidase, and amylase activities were assayed by the colorimetric method according to Guan, 1986.

A modified ingrowth core method (Hertel and Leuschner, 2002) was conducted to determine fine root production. Five stainless steel cubes $(20 \times 20 \times 20 \mathrm{~cm})$ with a $2 \mathrm{~mm}$ mesh were installed in each plot, 
and were refilled with rootless native soil in May 2019. The fine root in these in-growth blocks was collected at the end of October each year.

\section{Soil bacterial and fungal community analyses}

Soil microbial communities were assessed using amplicon-sequencing technology. In brief, microbial DNA from each soil sample was extracted using the E.Z.N.A. ® soil DNA Kit (Omega Bio-tek, Norcross, GA, USA) following the manufacturer's manual. The bacterial 16S rRNA and fungal ITS genes were amplified using the primers 515F/907R (Yusoff et al., 2013) and the primer ITS1F/ITS2R (Adams et al., 2013), respectively. The PCR and high-throughput sequencing were conducted by the Majorbio Company (Shanghai, China) using the Illumina MiSeq PE300 platform. Operational taxonomic units (OTUs) were classified at $97 \%$ similarity level using UPARSE (version 7.1), and chimeric sequences identified by UCHIME were discarded (Edgar, 2013). The taxonomy of bacteria and fungi was assigned by RDP Classifier (Wang et al., 2007) against the Silva and Unite database, respectively, with a $70 \%$ confidence threshold. All samples were rarefied to the minimum sequence of the sample before the following analyses. We analyzed microbial composition and diversity on a platform (www.i-sanger.com) of Majorbio Company.

\section{Data analysis}

The statistical analyses were carried out using SPSS version 24.0 for Windows (SPSS, Chicago, Illinois, USA). We used two-way ANOVA to test the effects of TFR and year on SR and its components, soil and root properties, microbial biomass, and enzymatic activities. We also used one-way ANOVA to assess the effects of TFR on fine root biomass and production, microbial community attributes (e.g., diversity, abundance).

Regression modeling was used to investigate the relationships between SR, HR, or AR and ST, as well as $S M$. The temperature sensitivity $\left(Q_{10}\right.$ value) was estimated by the following function (Lloyd and Taylor, 1994):

$$
R=\alpha e^{\beta T}
$$

where, $Q_{10}=e^{10 \beta}$;

$R$ represents SR, HR, and AR; $a$ and $\beta$ are fitted parameters; $T$ is the measured soil temperature.

Pearson correlation analyses were used to examine correlations between SR, HR, or AR and measured biotic and abiotic factors. Structure equation modeling (SEM) was conducted using AMOS 21.0 (SPSS Software, Chicago, Illinois, USA) to evaluate the significance of abiotic and biotic drivers in determining AR and HR (Wang et al., 2019). The SEM was fitted using the maximum likelihood estimation. The best model was selected using the lowest AIC value. 
We used random forest analysis to identify the statistically significant bacterial and fungal predictors (genera) for HR (Trivedi et al., 2016). A total of 219 bacterial genera and 46 fungal genera were selected in the random forest modeling. After that, we used linear regressions to assess the relationships between the relative abundance of the selected predictive genera and HR.

\section{Results}

\section{Soil physicochemical properties and soil enzymes}

TFR decreased SM by $28 \%$ and $23 \%$ for un-trenched subplots and trenched subplots, respectively $(P<$ 0.05), but did not change ST during the study periods (Fig. 1 and Table 1).

TFR had no significant effects on MBC and MBN (Table S1), and had little effects on measured enzyme activities except for polyphenolase $(P=0.08)$ (Table S1).

\section{Soil respiration and its components}

SR showed no significant difference between TFR and control in 2019 (2.48 \pm 0.23 vs. $2.63 \pm 0.19 \mu \mathrm{mol}$ $\left.\mathrm{CO}_{2} \mathrm{~m}^{-2} \mathrm{~m}^{-1}\right)$ and in 2020 ( $2.92 \pm 0.27$ vs. $\left.2.63 \pm 0.24 \mu \mathrm{mol} \mathrm{CO}_{2} \mathrm{~m}^{-2} \mathrm{~m}^{-1}\right)(P>0.05 ;$ Fig. 2 and Table 1$)$. TFR increased AR by $92 \%$ during the study periods $(P<0.05$; Table 1$)$, with respective interannual variation of $96 \%$ in 2019 and $88 \%$ in $2020(P<0.05$; Fig. 2$)$. TFR decreased HR by $23 \%$ during the study periods $(P=0.057$; Table 1$), 29 \%$ in $2019(P<0.05)$, and a slight decrease of $17 \%$ in $2020(P=0.09)$ (Fig. 2). TFR decreased relative contribution of HR to SR from $79 \%$ to $60 \%$ during the study periods $(P<0.05$; Fig. 3).

Table 1 Results ( $F$ and $P$ values) of two-way ANOVA for the effects of throughfall reduction (TFR), year $(Y)$ and their interactive effects (TFR $\times Y$ ) on $S R, H R, A R$, soil moisture, and soil temperature in un-trenched subplots (SM-U and ST-U) and trenched subplots (SM-T and ST-T ).

\begin{tabular}{|lllllll|}
\hline Variables & TFR & & Y & \multicolumn{3}{l|}{ TFR $\times Y$} \\
& F & $P$ & $F$ & $P$ & $F$ & $P$ \\
\hline SR & 0.38 & 0.847 & 0.32 & 0.580 & 0.31 & 0.582 \\
\hline HR & 4.10 & 0.057 & 0.05 & 0.834 & 0.38 & 0.544 \\
\hline AR & 9.10 & 0.007 & 2.23 & 0.151 & 0.18 & 0.678 \\
\hline SM-U & 12.41 & 0.002 & 0.01 & 0.931 & 0.24 & 0.630 \\
\hline SM-T & 26.48 & $<0.001$ & 0.61 & 0.445 & 0.09 & 0.762 \\
\hline ST-U & 0.01 & 0.943 & 0.01 & 0.775 & 0.001 & 0.970 \\
\hline ST-T & 0.01 & 0.926 & 0.06 & 0.809 & 0.04 & 0.843 \\
\hline
\end{tabular}




\section{Linking abiotic and biotic factors to soil $\mathrm{CO}_{2}$ efflux}

$\mathrm{SR}, \mathrm{HR}$, and AR were significantly related to soil temperature under both treatments (Fig. 4). TFR did not change the temperature sensitivity $\left(Q_{10}\right.$ value) of $S R$, while decreased the $Q_{10}$ value of $H R$ from 2.69 to 2.10 and increased the $Q_{10}$ value of $A R$ from 3.42 to 3.97 (Fig. 4). Soil moisture was significantly correlated with SR and HR $(P<0.05)$ although at a lower coefficient of determination, but not AR (Fig. 4).

TFR increased fine root biomass and production during the study periods ( $P<0.05$; Fig. 5), and was positively correlated with AR $(P<0.05)$ (Fig. 5). The SEM indicated that AR was directly controlled by fine root biomass (Fig. 7).

TFR significantly decreased bacterial richness $(P<0.05)$, and was marginally correlated with HR $(P=$ 0.07) (Fig. 6 and Table S2). The SEM also suggested that HR was directly driven by soil bacterial richness (Fig. 7). Our random forests modeling showed that many bacterial genera predictors of HR were distributed among the Proteobacteria, Acidobacteriota, Chloroflexi, and Actinobacteriota; fungal genera predictors of HR belong to the Ascomycota and Mucoromycota (Fig. S2). Some of these predictive genera were significantly related (linear regressions) to HR (Fig. 8). For example, TFR decreased the relative abundance of bacterial Novosphingobium, norank $11-24$ and norank Vicinamibacterales $(P<0.05)$ (Table S4), and were positively related to HR (Fig. 8). TFR increased the abundance of bacterial 1959-1 and norank Acidimicrobiia $(P<0.05)$ (Table S4), and were negatively associated with HR (Fig. 8). In addition, TFR increased the relative abundance of fungal Leptobacillium $(P<0.05$; Table S4), and was negatively related to HR (Fig. 8).

\section{Discussion}

\section{Effects of TFR on HR, AR and SR}

Consistent with those of other studies (Borken et al., 2006; Risk et al., 2012), we also found long-term TFR decreased HR. TFR significantly decreased bacterial richness, which may lead to the decreased HR due to the positive correlation between bacterial diversity and soil $\mathrm{CO}_{2}$ efflux (Liu et al., 2018; Delgado-Baquerizo et al., 2016). Generally, greater microbial species richness can allow for more metabolic activities, promoting the decomposition of organic matter (Naylor and Coleman-Derr, 2018). Thus, the decreased HR after 6-year consecutive TFR could arise from the decreased bacterial diversity (Hutchins et al., 2019; Singh et al., 2010). Another study in this oak forest has shown that short-term variation in soil moisture had no significant impact on bacterial diversity (Wei et al., 2018), which may explain the unchanged HR under TFR treatment during the first four years (Lu et al., 2017).

We subsequently identified major microbial taxa (genera) that predicted the changes in HR. We found the relative abundance of Novosphingobium, norank 11-24 and norank Vicinamibacterales belong to Gramnegative bacteria were positively associated with HR. In addition, the relative abundance of 1959-1 and 
norank Acidimicrobiia belong to Gram-positive bateria were negatively related to HR. Studies have shown that soils with a high abundance of oligotrophs or low abundance of copiotrophs may have low $\mathrm{CO}_{2}$ emissions (Trivedi et al., 2013; Liu et al., 2018). It has also been shown that the Gram-negative bacteria have characteristics of copiotrophs, while Gram-positive bacteria contain characteristics of oligotrophs (Naylor and Coleman-Derr, 2018). Thus, the TFR-induced changes in the relative abundance of these bacterial taxa were responsible for the decreased HR. In addition, we found the relative abundance of fungal Leptobacillium belong to Ascomycota were negatively correlated to HR, despite a weak correlation between overall fungal community diversity with HR. We know little about the mechanism of the association between Leptobacillium and $\mathrm{C}$ emission, and postulated the taxa are tolerant to drought and may have high $C$ use efficiency (Liu et al., 2018).

Previous studies have suggested that experimental drought often reduced AR due to the decreased fine root biomass or belowground $C$ allocation among different ecosystems (Hinko-Najera et al., 2015; Huang et al., 2018; Zhou et al., 2019). However, we found long-term TFR increased AR, mainly because of higher fine root biomass and production under the TFR. According to the optimal partitioning theory (Bloom et al., 1985), plants should allocate more $C$ to root growth from aboveground parts to reduce water limitation (Fuchslueger et al., 2014). However, many field throughfall exclusion experiments of forests have shown that fine root biomass did not always support this theory, including increase (Zhou et al., 2020), decrease (Moser et al., 2014), or little change during the first four years in this study (Lu et al., 2017), indicating that the responses of fine root to water deficit depends on intensity and duration of drought. In our system, we argued that mature trees increased belowground $\mathrm{C}$ allocation to adapt to the long-term drought, resulting in the higher AR.

Contrary to other studies (Sotta et al., 2007; Cleveland et al., 2010), we found long-term TFR had no significant effect on SR. Another study also showed that drought had no significant impact on soil $\mathrm{CO}_{2}$ flux but did not mention AR and HR in a tropical forest (Davidson et al. 2008). This may mask the contrasting responses of AR and HR to long-term drought due to the different sensitivities of fine roots and microbes to water deficit (Zhou et al., 2019). Here, the present result showed AR and HR had opposite responses after 6-year consecutive TFR, leading to the unchanged SR.

\section{Seasonal variability of soil $\mathrm{CO}_{2}$ efflux}

The pronounced seasonal variations of $\mathrm{SR}, \mathrm{AR}$, and HR were explained by soil temperature, which was in agreement with previous studies (Vincent et al., 2006; Liu et al., 2016). Besides $\otimes$ soil moisture can also partly explained the seasonal patterns of SR and HR. These indicated that soil temperature and soil moisture can solely control soil respiration through influencing decomposition rates and microbial activity (Barthel et al., 2011). However, we found a weak relationship between soil moisture and AR along with the seasonal changes. This did not mean that soil moisture was not important to roots, but it may be the inherent growth rhythm of roots and the utilization of deep soil water that masked the effect of soil moisture on $A R$. TFR increased the $Q_{10}$ of $A R$ while decreased it of $H R$. The changed $Q_{10}$ value may reflect 
the shifts in the physiological status of plant roots and soil microbes (Zhang et al., 2014), which was potentially important for C-climate feedback models, and needs to be further evaluated.

Specifically, we found HR showed little difference between control and TFR in May and October 2020 (Fig. 2). A similar pattern was also found in AR in both 2019 and 2020 (Fig. 2). This may be attributed to the lower activities of both roots and soil microorganisms in May and October, and hence lower water requirement (Chapin et al., 2002). It is worth noting that the maximum AR in July 2019 and 2020 can determine the response of SR to drought, and thus the monitoring frequency of SR should be increased to accurately assess the response of SR to drought.

\section{Relative contribution of AR and HR to SR}

Although partitioning AR and HR of SR and evaluating the responses of AR and HR to drought is vital to understanding whether and how drought facilitates soil $C$ sequestration, there was limited research on this crucial issue in the warm-temperate forests of China (Luan et al., 2012; Liu et al., 2016; Lu et al., 2017). We used the trenching method to distinguish AR and HR, which was widely applied in forest ecosystems (Liu et al., 2016; Huang et al., 2018). This method may underestimate HR due to the elimination of roots and associated root exudations, which are respired by soil microbes and often lead to a priming effect resulting from SOC decomposition (Hanson et al., 2000). It may also overestimate HR due to the elevated soil moisture in the trenched subplots (Yan et al., 2010). Moreover, the AR in our study may be overestimated as the estimation of AR includes both root respiration and rhizosphere respiration (e.g., mycorrhizal respiration) (Hopkins et al., 2013).

Nevertheless, our study provides empirical evidence that long-term TFR decreased the relative contribution of $\mathrm{HR}$ to $\mathrm{SR}$, indicating that the proportion of $\mathrm{CO}_{2}$ released from microbial SOM decomposition was lower than that from root activities under TFR treatment. As is known to all, HR is an important indicator of SOC decomposition and also plays a crucial role in the stability of SOC (Janssens et al., 2010). Therefore, the decreased relative contribution of HR to SR may lead to more soil C sink (Wang et al., 2019). On the other hand, soil $C$ storage is also largely dependent on the $C$ input (Riggs et al., 2015), thus the higher fine root biomass and production under TFR treatment may also facilitate soil $C$ sequestration. However, recent studies have demonstrated that plant roots or belowground $\mathrm{C}$ allocation can drive the soil SOM decomposition (Moore et al., 2020; Street et al., 2020), indicating that the fine roots had a dual role in regulating soil $C$ storage (Dijkstra et al., 2020). Our results suggest that how prolonged drought will ultimately influence SR, and therefore soil C storage, will depend not only on soil microorganisms but also on plant belowground $\mathrm{C}$ allocation.

\section{Conclusions}

In this warm-temperate oak forest, long-term TFR decreased HR and was positively associated with bacterial richness. More importantly, some bacterial taxa such as Novosphingobium and norank Acidimicrobiia, and fungal Leptobacillium were identified as the key drivers of HR. However, TFR 
significantly increased $A R$, which was attributed to to the increased fine root biomass and production. The increase in AR offset the decrease in HR, resulting in unaltered SR under the TFR treatment. Our findings highlight the different response mechanisms of AR and HR to prolonged drought should be considered when predicting soil $\mathrm{CO}_{2}$ emissions under future droughts.

\section{Abbreviations}

SR: soil respiration; AR: autotrophic respiration; HR: heterotrophic respiration; TFR: throughfall reduction; SOM: soil organic decomposition; SM: soil moisture; ST: soil temperature; SOC: soil organic carbon; C: carbon; N: nitrogen; P: phosphorus; NSC: nonstructural carbohydrates; MBC: microbial biomass C; MBN: microbial biomass nitrogen; SEM: structure equation modeling.

\section{Declarations}

\section{Acknowledgements}

We would like to thank the Baotianman Forest Ecosystem Research Station for experimental maintenance and Xiaodong Niu and Xiang Li for assistance in fieldwork.

\section{Authors' contributions}

Conceived and design the experiment: Shirong Liu, Jinglei Zhang. Obtained data and samples in the field: Jinglei Zhang, Cuiju Liu, Xiaojing Liu. Processed samples in the lab: Jinglei Zhang, Xingwei Guo, Baoliang Niu. Analyzed the data and wrote the manuscript: Jinglei Zhang, Shirong Liu, Junwei Luan, Hui Wang, Cuiju Liu. All authors read and approved the final manuscript.

\section{Funding}

This study was supported by the National Key Technology R\&D Program of China (NO. 2018YFC0507301) and by Research and Development Project of RIFEEP, Chinese Academy of Forestry (99802-2020).

\section{Availability of data and materials}

The datasets used during the current study are available from the corresponding author on reasonable request.

\section{Ethics approval and consent to participate}

Not applicable.

\section{Consent for publication}

Not applicable. 


\section{Competing interests}

The authors declare that they have no competing interests.

\section{References}

Adams RI, Miletto M, Taylor JW, Bruns TD (2013) Dispersal in microbes: fungi in indoor air are dominated by outdoor air and show dispersal limitation at short distances. ISME J 7:1262-1273.

Bao SD (2000) Soil Agricultural Chemistry Analysis, Third ed. China Agriculture Press.

Barthel M, Hammerle A, Sturm P, Baur T, Gentsch L, Knohl A (2011) The diel imprint of leaf metabolism on the $\mathrm{d}^{13} \mathrm{C}$ signal of soil respiration under control and drought conditions. New Phytol 192:925-938.

Batson J, Noe GB, Hupp CR, Krauss KW, Rybicki NB, Schenk ER (2015) Soil greenhouse gas emissions and carbon budgeting in a short-hydroperiod floodplain wetland. J Geophys Res-Biogeo 120:77-95.

Bloom AJ, Chapin FSIII, Mooney HA (1985) Resource limitation in plants-an economic analogy. Annu Rev Ecol Syst 16:363-392.

Borken W, Savage K, Davidson EA, Trumbore SE (2006) Effects of experimental drought on soil respiration and radio carbon efflux from a temperate forest soil. Glob Chang Biol 12:177-193

Chapin FS, Matson PA, Mooney HA (2002) Principles of Terrestrial Ecosystem Ecology. New York, USA: Springer.

Cleveland CC, Wieder WR, Reed SC, Townsend AR (2010) Experimental drought in a tropical rain forest increases soil carbon dioxide losses to the atmosphere. Ecology 91:2313-2323.

da Costa ACL, Metcalfe DB, Doughty CE, de Oliveira AAR, Neto GFC, da Costa MC, Silva Junior JdA, Aragão LEOC, Almeida S, Galbraith DR, Rowland LM, Meir P, Malhi Y (2013) Ecosystem respiration and net primary productivity after 8-10 years of experimental through-fall reduction in an eastern Amazon forest. Plant Ecol Divers 7:7-24.

Davidson EA, Nepstad DC, Ishida FY, Brando PM (2008) Effects of an experimental drought and recovery on soil emissions of carbon dioxide, methane, nitrous oxide, and nitric oxide in a moist tropical forest. Glob Chang Biol 14:2582-2590.

Delgado-Baquerizo M, Giaramida L, Reich PB, Khachane AN, Hamonts K, Edwards C, Lawton LA, Singh BK, (2016) Lack of functional redundancy in the relationship between microbial diversity and ecosystem functioning. J Ecol 104:936-946.

Dijkstra FA, Zhu B, Cheng WX (2020) Root effects on soil organic carbon: a double-edged sword. New Phytol doi: 10.1111/nph.17082. 
Edgar RC (2013) UPARSE: highly accurate OTU sequences from microbial amplicon reads. Nat Methods 10: $996-998$.

Fuchslueger L, Bahn M, Fritz K, Hasibeder R, Richter A (2014) Experimental drought reduces the transfer of recently fixed plant carbon to soil microbes and alters the bacterial community composition in a mountain meadow. New Phytol 201:916-927.

Gao JF (2006) Instruction for Plant Physiology Experiments. Beijing: Higher Education Press.

Guan SY (1986) Soil Enzyme and Its Research Methods. Beijing: Agricultural Press.

Hanson PJ, Edwards NT, Garten CT, Andrews JA (2000) Separating root and soil microbial contributions to soil respiration: A review of methods and observations. Biogeochemistry 48:115-146.

Hertel D, Leuschner C (2002) A comparison of four different fine root production estimates with ecosystem carbon balance data in a Fagus-Quercus mixed forest. Plant Soil 239:237-251.

Hinko-Najera N, Fest B, Livesley SJ, Arndt S (2015) Reduced throughfall decreases autotrophic respiration: but not heterotrophic respiration in a dry temperate broadleaved evergreen forest. Agric For Meteorol 200:66-77.

Hopkins F, Gonzalez-Meler M, Flower C, Lynch D, Czimczik C, Tang J, Subke J (2013). Ecosystem-level controls on root-rhizosphere respiration. New Phytol 199:339-351.

Huang S, Ye G, Lin J, Chen K, Xu X, Ruan H, Tan F, Chen HYH (2018) Autotrophic and heterotrophic soil respiration responds asymmetrically to drought in a subtropical forest in the Southeast China. Soil Biol Biochem 123:242-249.

Hutchins DA, Jansson JK, Remais JV, Rich V I, Singh B K, Trivedi P (2019) Climate change microbiology problems and perspectives. Nat Rev Microbiol 17:391-396.

IPCC (2013) Working Group I Contribution to the IPCC Fifth Assessment Report. Climate Change 2013: The physical science basis summary for policymakers, Cambridge, UK/New York, NY, USA.

Janssens IA, Dieleman W, Luyssaert S, Subke JA, Reichstein M, Ceulemans R, Ciais P, Dolman AJ, Grace J, Matteucci G, Papale D, Piao SL, Schulze ED, Tang J, Law BE (2010). Reduction of forest soil respiration in response to nitrogen deposition. Nat Geosci 3:315-322.

Janssens IA, Lankreijer $\mathrm{H}$, Matteucci G, et al. Productivity overshadows temperature in determining soil and ecosystem respiration across European forests. Glob Chang Biol 2001, 7(3), 269-278.

Liu YC, Liu SR, Wan SQ, Wang JX, Luan JW, Wang H (2016) Differential responses of soil respiration to soil warming and experimental throughfall reduction in a transitional oak forest in central China. Agric For Meteorol 226-227:186-198. 
Liu YR, Delgado-Baquerizo M, Wang JT, Hu HW, Yang Z, He JZ (2018) New insights into the role of microbial community composition in driving soil respiration rates. Soil Biol Biochem 118:35-41.

Lloyd J, Taylor JA (1994) On the temperature dependence of soil respiration. Functional Ecology 8:315323.

Lu HB, Liu SR, Wang H, Luan JW, Schindlbacher A, Liu YC, Wang Y (2017) Experimental throughfall reduction barely affects soil carbon dynamics in a warm-temperate oak forest, central China. Sci Rep 7:15099.

Luan JW, Liu SR, Wang JX, Zhu XL, Shi ZM (2011) Rhizospheric and heterotrophic respiration of a warmtemperate oak chronosequence in China. Soil Biol Biochem 43:503-512.

Luan JW, Liu SR, Zhu XL, Wang JX, Liu K (2012) Roles of biotic and abiotic variables in determining spatial variation of soil respiration in secondary oak and planted pine forests. Soil Biol Biochem 44:143150.

Luo Y, Zhou X (2006) Soil respiration and the environment. Academic Press, Elsevier.

Metcalfe DB, Meir P, Aragão LEOC, Malhi Y, da Costa ACL, Braga A, Gonçalves PHL, de Athaydes J, de Almeida SS, Williams M (2007) Factors controlling spatio-temporal variation in carbon dioxide efflux from surface litter, roots, and soil organic matter at four rain forest sites in the eastern Amazon. J Geophys Res-Biogeo 112:G04001.

Moore JAM, Sulman BN, Mayes MA, Patterson CM, Classen AT (2020) Plant roots stimulate the decomposition of complex, but not simple, soil carbon. Funct Ecol 34:899-910.

Moser G, Schuldt B, Hertel D, Horna V, Coners H, Barus H, Leuschner C (2014) Replicated throughfall exclusion experiment in an Indonesian perhumid rainforest: wood production, litter fall and fine root growth under simulated drought. Glob Chang Biol 20:1481-1497.

Riggs C, Hobbie S, Bach E, Hofmockel K, Kazanski C (2015) Nitrogen addition changes grassland soil organic matter decomposition. Biogeochemistry 125:203-219.

Risk D, Nickerson N, Phillips C, Kellman L, Moroni M (2012) Drought alters respired $\delta^{13} \mathrm{CO}_{2}$ from autotrophic: but not heterotrophic soil respiration. Soil Biol Biochem 50:26-32.

Schindlbacher A, Wunderlich S, Borken W, Kitzler B, Zechmeister-Boltenstern S, Jandl R (2012) Soil respiration under climate change: prolonged summer drought offsets soil warming effects. Glob Chang Biol 18:2270-2279.

Selsted M B, van der Linden L, Ibrom A, Michelsen A, Larsen KS, Pedersen JK, Mikkelsen TN, Pilegaard K, Beier $C$, Ambus $P$ (2012) Soil respiration is stimulated by elevated $\mathrm{CO}_{2}$ and reduced by summer drought: 
three years of measurements in a multifactor ecosystem manipulation experiment in a temperate heathland (CLIMAITE). Glob Chang Biol 18:1216-1230.

Singh BK, Bardgett R D, Smith P, Reay DS (2010) Microorganisms and climate change: terrestrial feedbacks and mitigation options. Nat Rev Microbiol 8:779-790.

Sotta ED, Veldkamp E, Schwendenmann L, Guimaraes BR, Paixao RK, Ruivo M, da Costa L, Carlos A, Meir $P(2007)$ Effects of an induced drought on soil carbon dioxide $\left(\mathrm{CO}_{2}\right)$ efflux and soil $\mathrm{CO}_{2}$ production in an Eastern Amazonian rainforest, Brazil. Glob Chang Biol 13:2218-2229.

Street LE, Garnett MH, Subke JA, Baxter R, Dean JF, Wookey PA (2020) Plant carbon allocation drives turnover of old soil organic matter in permafrost tundra soils. Glob Chang Biol. 26:4559-4571.

Sun SQ, Lei HQ, Chang SX (2019) Drought differentially affects autotrophic and heterotrophic soil respiration rates and their temperature sensitivity. Biol and Fert Soils 55:275-283.

Tian H, Melillo JM, Kicklighter DW, McGuire AD, Helfrich J, Moore B, Vorosmarty CJ (2000) Climatic and biotic controls on annual carbon storage in Amazonian ecosystems. Glob Ecol Biogeogr 9:315-335.

Trivedi P, Anderson IC, Singh BK (2013) Microbial modulators of soil carbon storage: integrating genomic and metabolic knowledge for global prediction. Trends Microbiol 21:641-651.

Trivedi P, Delgado-Baquerizo M, Trivedi C, Hu HW, Anderson IC, Jeffries TC, Zhou J, Singh B (2016) Microbial regulation of the soil carbon cycle: evidence from gene-enzyme relationships. ISME J 10:25932604.

Vance E, Brookes P, Jenkinson D (1987) An extraction method for measuring soil microbial biomass C. Soil Biol Biochem 19:703-707.

Vidon P, Marchese S, Welsh M, McMillan S (2016) Impact of precipitation intensity and riparian geomorphic characteristics on greenhouse gas emissions at the soil-at-mosphere interface in a waterlimited riparian zone. Water Air Soil Pollut 227:1-12.

Vincent G, Shahriari AR, Lucot E, Badot PM, Epron D (2006) Spatial and seasonal variations in soil respiration in a temperate deciduous forest with fluctuating water table. Soil Biol Biochem 38:25272535.

Wang J S, Song B, Ma FF, Tian DS, Li Y, Yan T, Quan Q, Zhang FY, Li ZL, Wang BX, Gao Q, Chen WN, Niu SL (2019) Nitrogen addition reduces soil respiration but increases the relative contribution of heterotrophic component in an alpine meadow. Funct Ecol 33:2239-2253.

Wang Q, Garrity GM, Tiedje JM, Cole JR (2017) Naive Bayesian classifier for rapid assignment of rRNA sequences into the new bacterial taxonomy. Appl Env Microbiol 73:5261-5267. 
Wang X, Liu LL, Piao SL, Janssens IA, Tang JW, Liu WX, Chi Y, Wang J, Xu S (2014) Soil respiration under climate warming: differential response of heterotrophic and autotrophic respiration. Glob Chang Biol 20: 3229-3237.

Wei H, Peng CH, Yang B, Song HX, Li Q, Jiang L, Wei G, Wang KF, Wang H, Liu XJ, Chen DX, Li YD, Wang M (2018) Contrasting soil bacterial community, diversity, and function in two forests in China. Front Microbiol 9:1693.

Wu J, Joergensen R, Pommerening B, Chaussod R, Brookes P (1990) Measurement of soil microbial biomass $C$ by fumigation-extraction - an automated procedure. Soil Biol Biochem 22:1167-1169.

Yan LM, Chen SP, Huang JH, Lin GH (2010) Differential responses of auto- and heterotrophic soil respiration to water and nitrogen addition in a semiarid temperate steppe. Glob Chang Biol 16:23452357.

Yusoff MZM, Hu A, Feng C, Maeda T, Shirai Y, Hassan MA, Yu CP (2013) Influence of pretreated activated sludge for electricity generation in microbial fuel cell application. Bioresource technol 145:90-96.

Zhang C, Niu D, Hall SJ, Wen H, Li X, Fu H, Wan C, Elser JJ (2014) Effects of simulated nitrogen deposition on soil respiration components and their temperature sensitivities in a semiarid grassland. Soil Biol Biochem 75: 113-123.

Zhang X, Zhang Y, Sha L, Wu C, Tan Z, Song Q, Liu Y, Dong L (2015) Effects of continuous drought stress on soil respiration in a tropical rainforest in southwest China. Plant Soil 394:343-353.

Zhou GY, Zhou XH, Liu RQ, Du ZG, Zhou LY, Li SS, Liu HY, Shao JJ, Wang JW, Nie YY, Gao J, Wang MH, Zhang MY, Wang XH, Bai SH (2020) Soil fungi and fine root biomass mediate drought-induced reductions in soil respiration. Funct Ecol 34:2634-2643.

Zhou L, Liu Y, Zhang Y, Sha L, Song Q, Zhou W, Li J (2019) Soil respiration after six years of continuous drought stress in the tropical rainforest in Southwest China. Soil Biol Biochem 138:1-11.

\section{Figures}




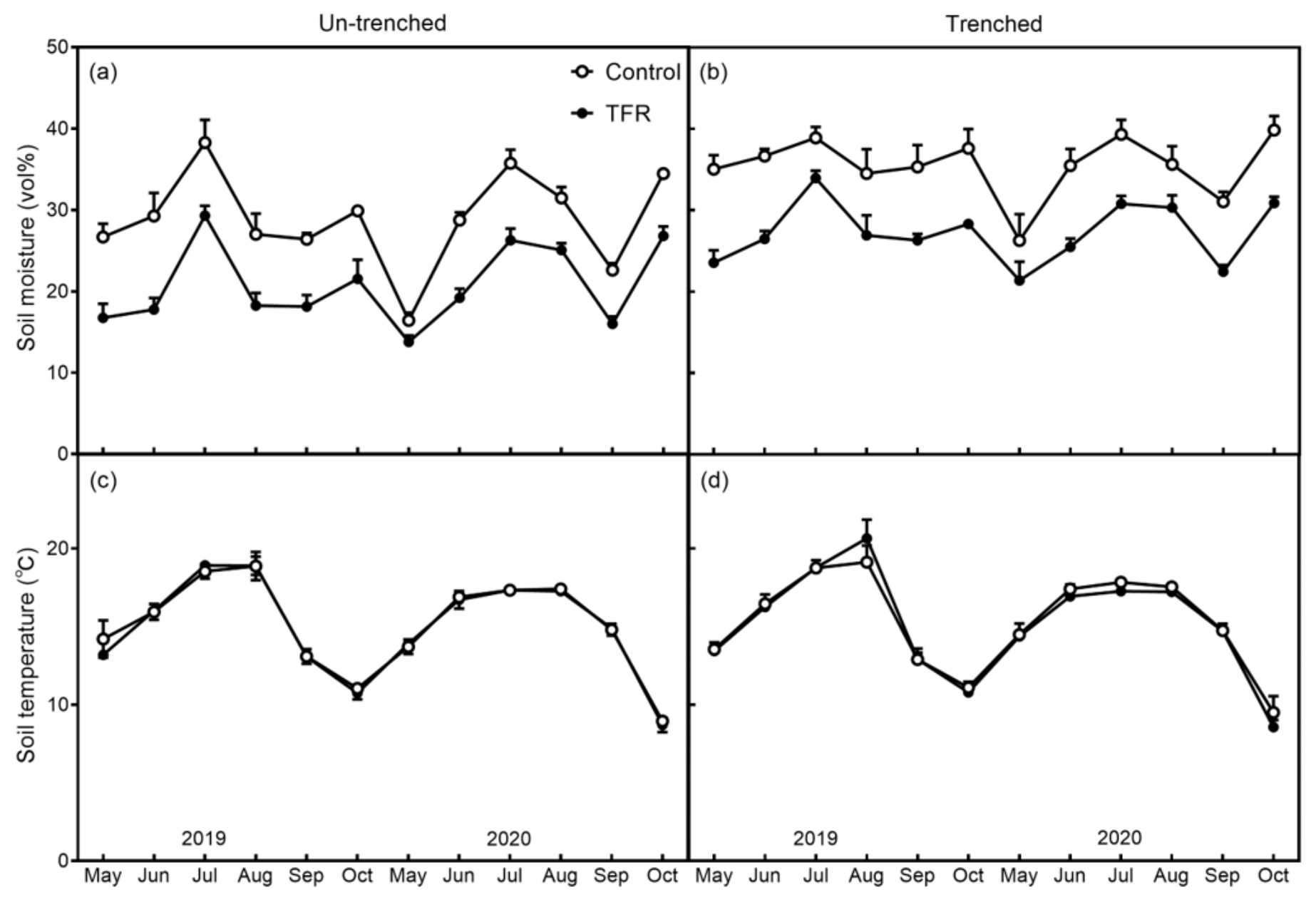

Figure 1

Effects of TFR on seasonal variability of soil temperature (ST; $a$ and b) and soil moisture (SM; c and d) for the un-trenched and trenched subplots from 2019 to 2020. Error bars represent the mean standard error. 


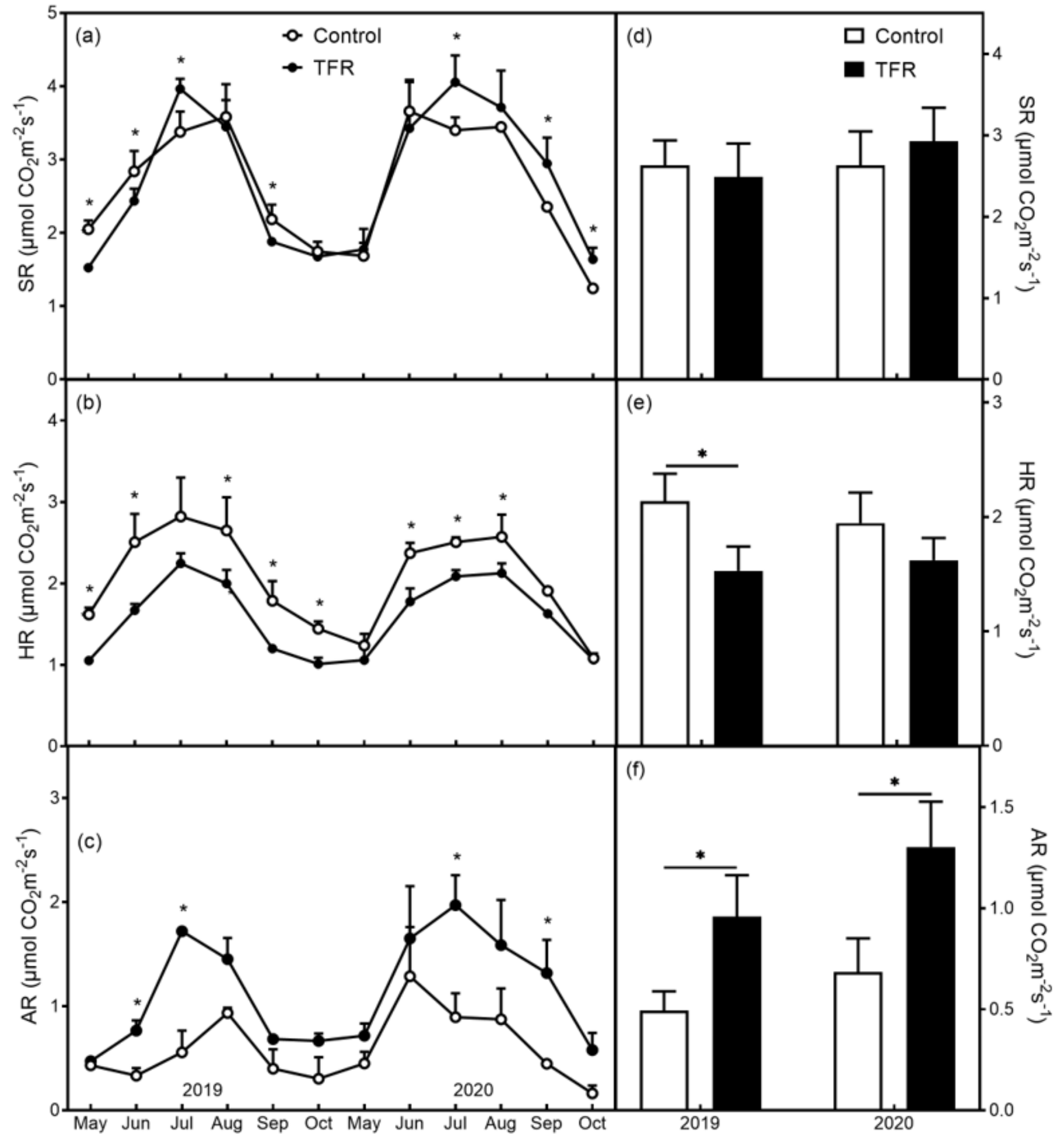

Figure 2

Seasonal variation and average value of SR $(a, d), H R(b, e)$ and $A R(c, f)$ from 2019 to 2020. ${ }^{*}<0.05$. 

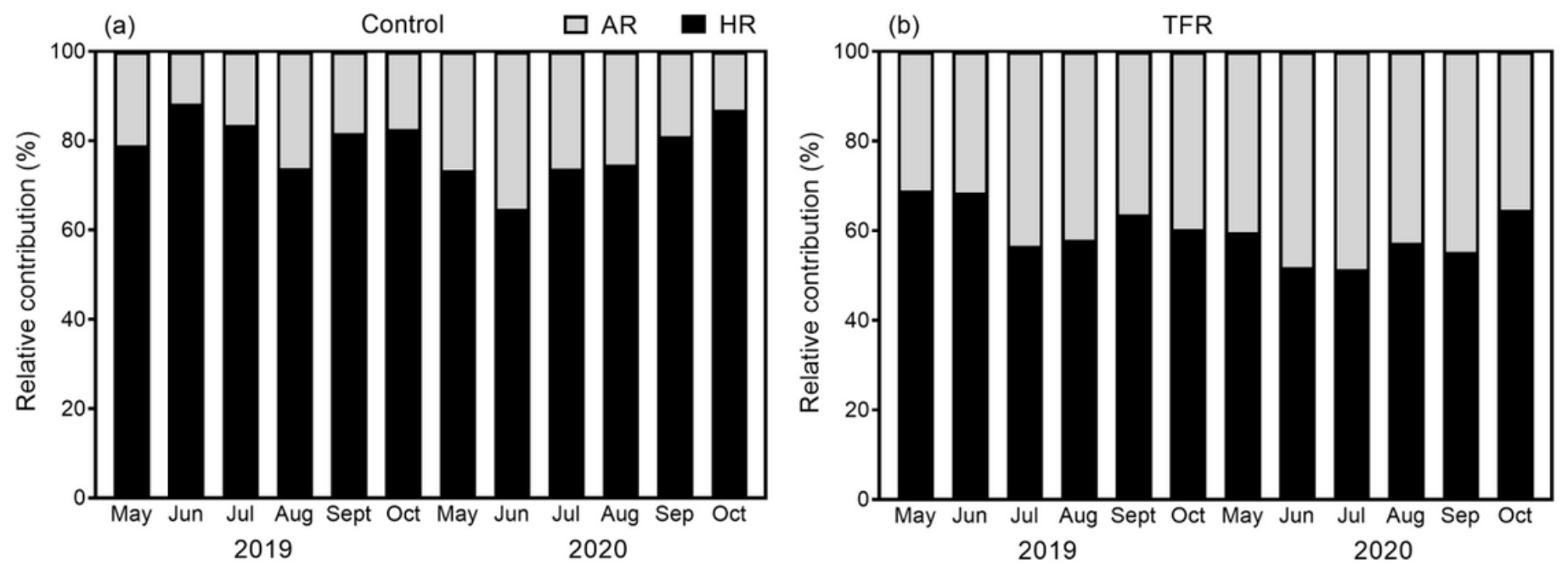

Figure 3

Seasonal variability in the relative contribution of AR and HR to SR under control (a) and TFR treatment (b). 


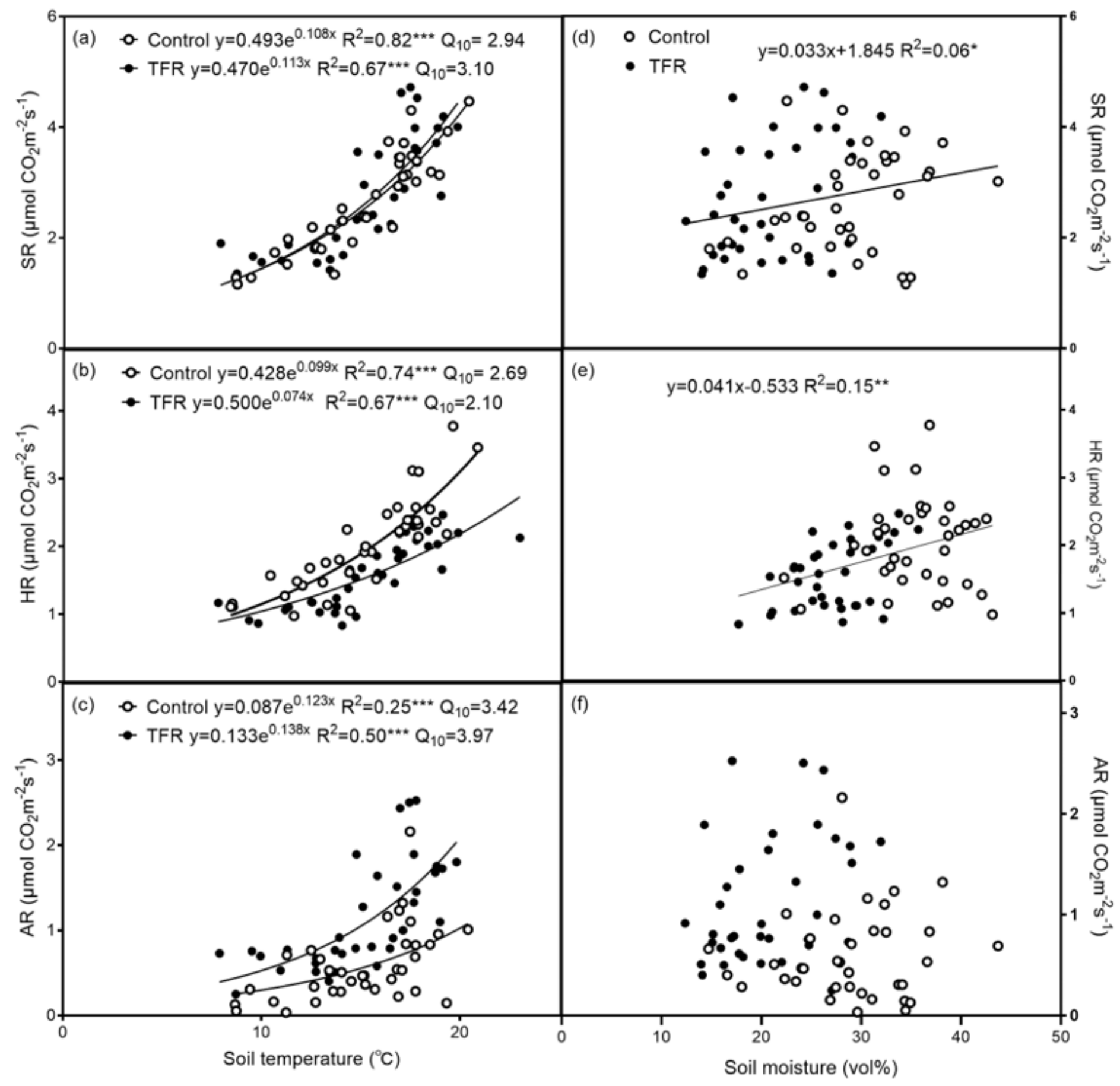

Figure 4

Relationships between soil temperature and SR (a), HR (b), and AR (c), and relationships between soil moisture and SR (d), HR (e) and AR (f) under control and TFR treatment. ${ }^{*} P<0.05,{ }^{*} \mathrm{P}<0.01,{ }^{\star \star *} \mathrm{P}<$ 0.001 . 

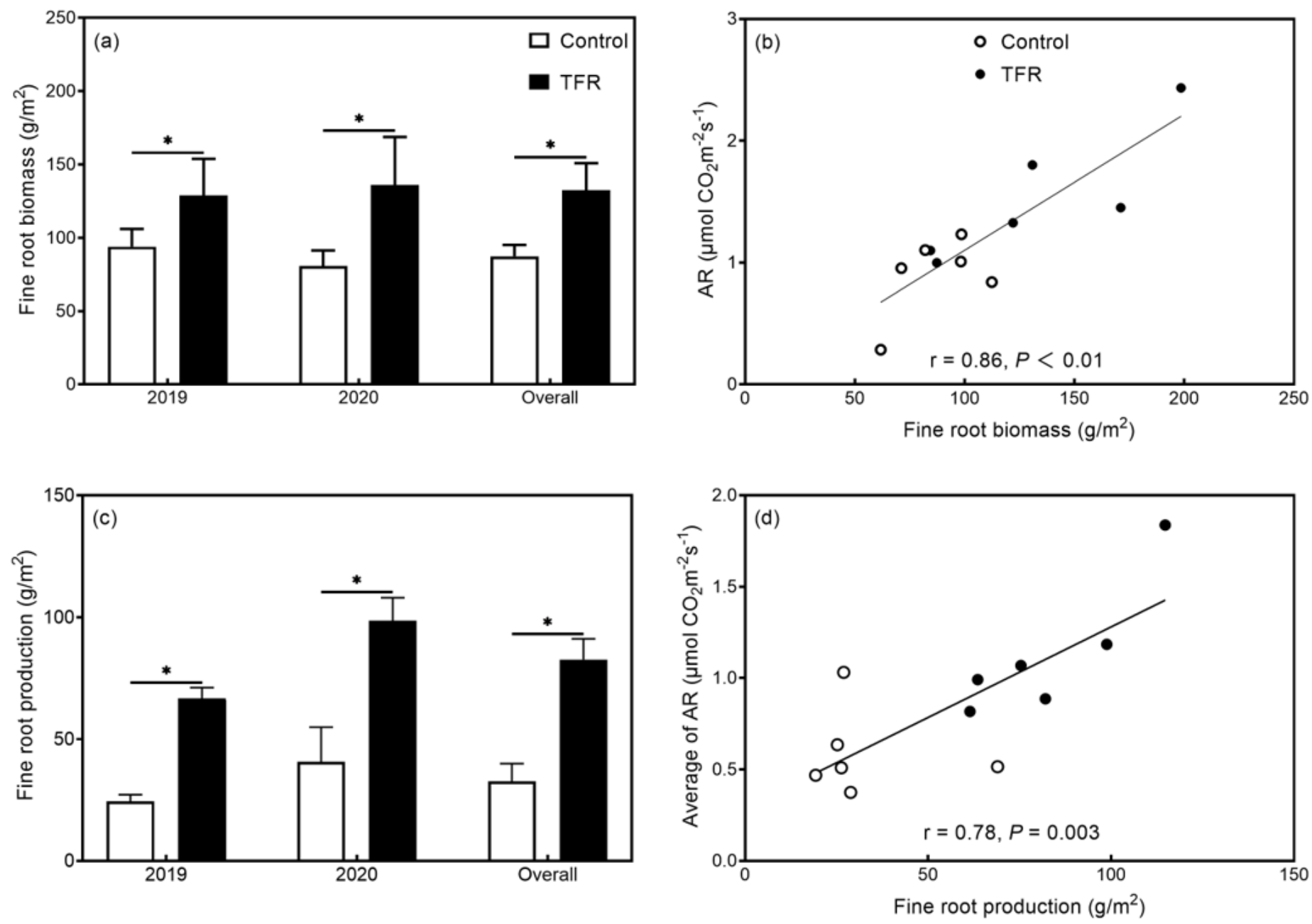

Figure 5

Fine root biomass (a) and production (c) under control and TFR treatment, and relationships between fine root biomass and $A R(b)$, between fine root production and the average of $A R(d)$. ${ }^{*} P<0.05$. 

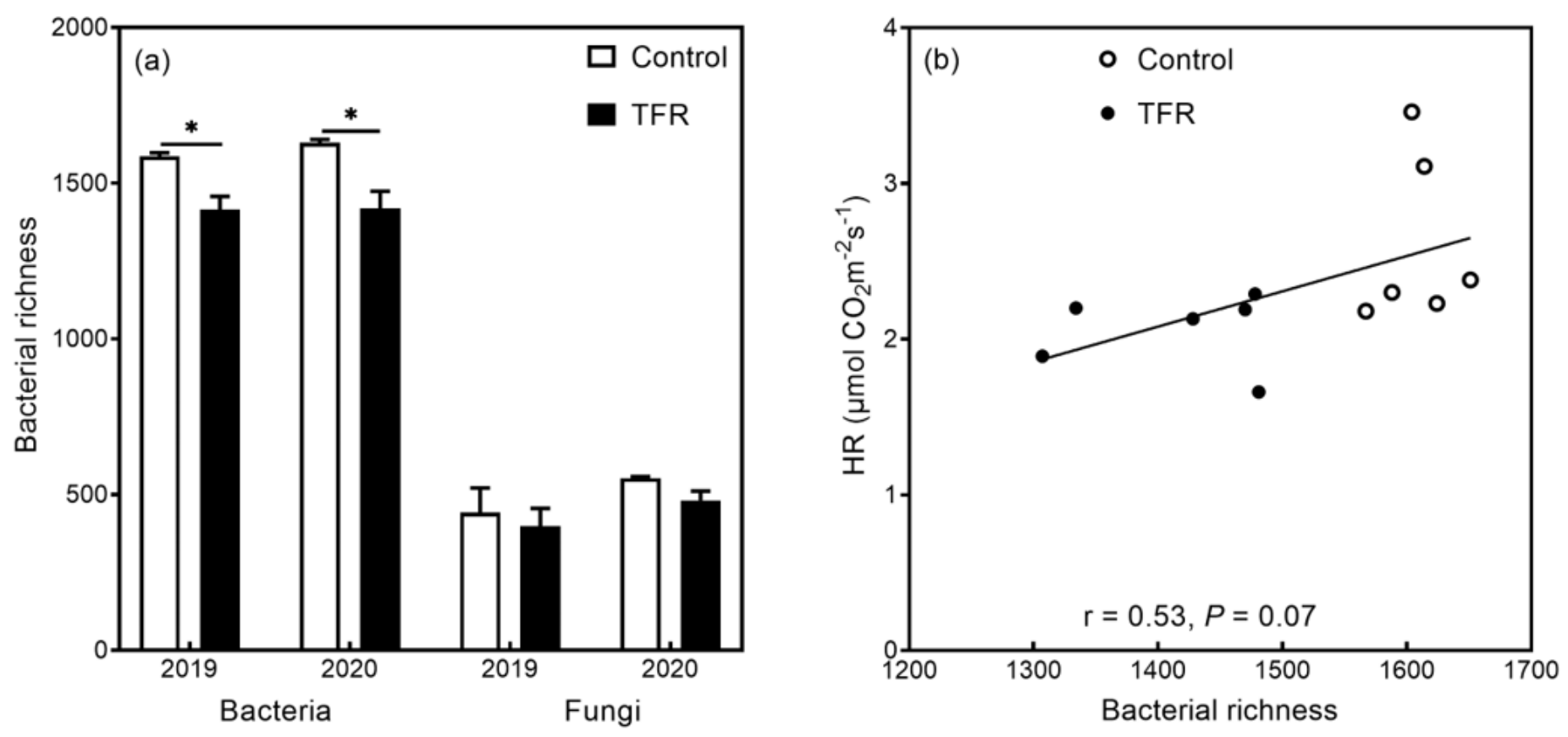

Figure 6

Effects of TFR on bacterial and fungal richness (Sobs index) (a), and relationships between bacterial richness and $A R(b) .{ }^{*} P<0.05$. 


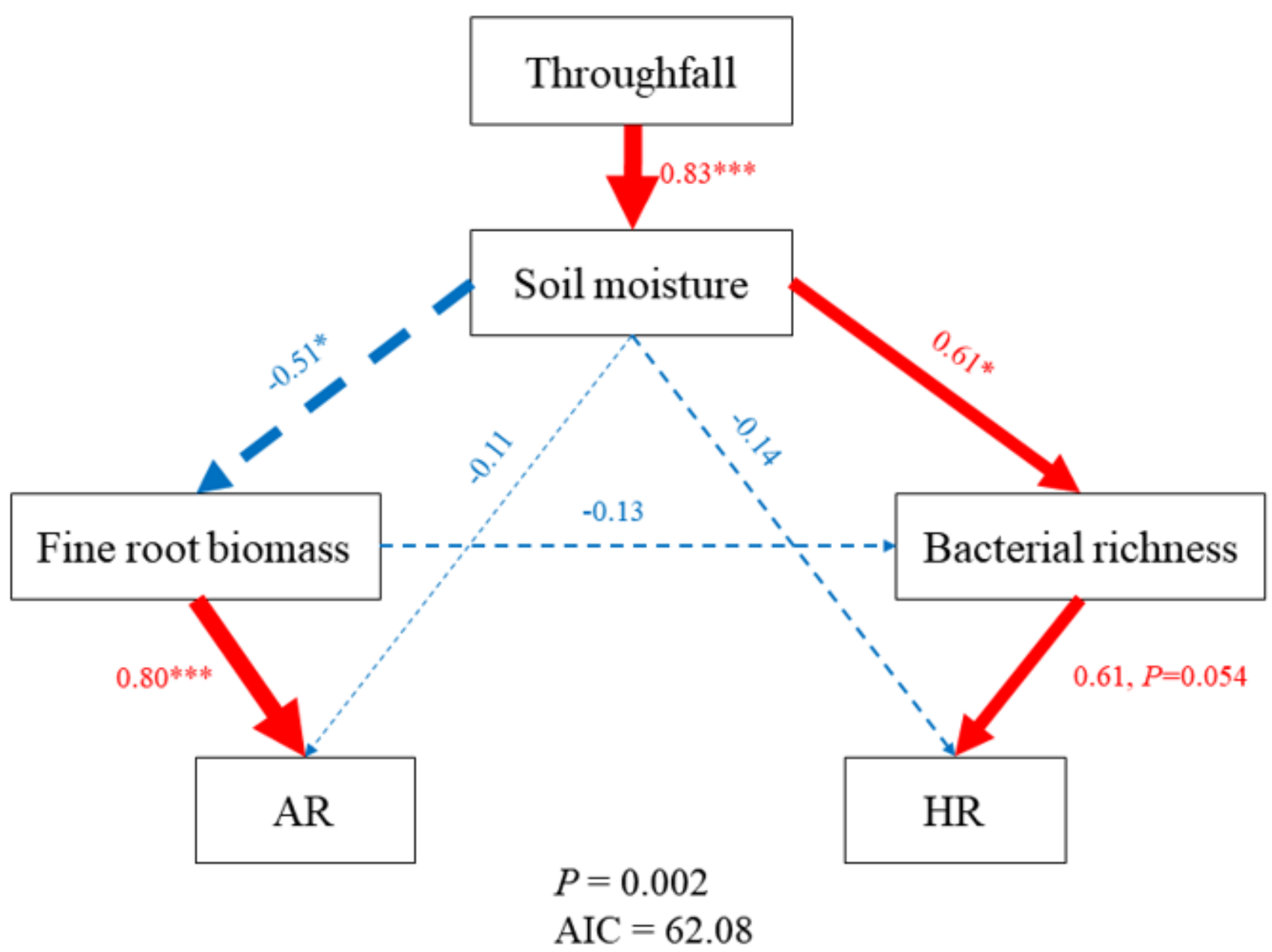

Figure 7

Structure equation modeling (SEM) assessing the direct and indirect influences of driving factors on AR and HR. Blue and red arrows indicate negative and positive relationships, respectively. The numbers on arrows are standardized path coefficients, and arrow width is proportional to the strength of the relationship. ${ }^{*} P<0.05,{ }^{*} \mathrm{P}<0.01,{ }^{*} * \mathrm{P}<0.001$. 

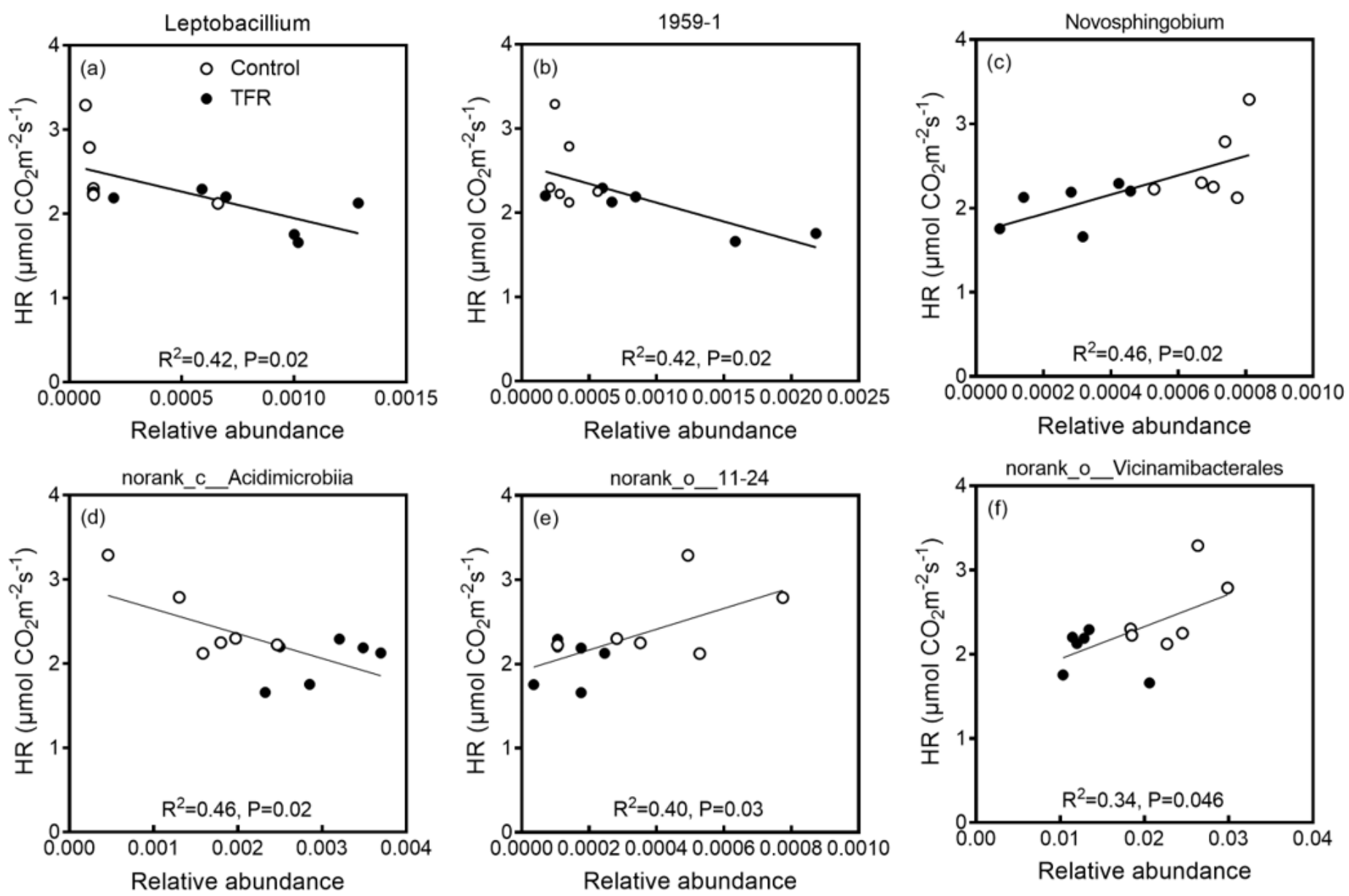

Figure 8

Linear regressions between the relative abundances of selected microbial genera and HR across different treatment.

\section{Supplementary Files}

This is a list of supplementary files associated with this preprint. Click to download.

- supplement.docx 